\title{
EDUCACIÓN ARTÍSTICA INICIAL RESIGNIFICADA
}

\author{
Rosío Muñoz León \\ Universidad Diego Portales, Chile. Fono: +56954640499 Correo electrónico: \\ rosio.munoz@mail.udp.cl
}

Estimado Sr. Editor:

$\mathrm{El}$ arte suele ser una temática de gran interés que entusiasma a grandes y chicos. La creación artística se vincula directamente con la cultura, con la reflexión y la crítica, con los anhelos y temores; con lo que el artista quiere presentar, quiere expresar.

La educación artística tiene la compleja tarea de acercar a los educandos a un mundo de posibilidades de creación y apreciación, siendo la mediación de nuevos artistas.

Si bien, en educación básica y media existen profesores "especialistas en artes", esto no ocurre en educación parvularia. Las y los educadores de párvulos debemos ser mediadores transversales de los aprendizajes esperados, incluyendo de los lenguajes artísticos, elaborando estrategias pedagógicas en aula, y desarrollando competencias didácticas adaptables a distintos entornos y desafíos.

En ese sentido, la importancia de la formación artística inicial debe ser reivindicada.Por un lado, me refiero a la necesidad de revisar nuestras creencias, de investigar y de abordar la educación artística en niños y niñas de 0 a 6 años. Tal como señalan Lowenfeld y Brittain (1980), el arte contribuye al desarrollo de aprendizajes ligados a la interacción del niño con su ambiente; en un comienzo como actividad kinésica placentera, y posteriormente de forma intencionada y expresiva. Las artes, bien utilizadas, son una herramienta fundamental en acercar el mundo a los pequeños. Y la ausencia de dicha exposición en los primeros años de educación -período en que se sientan las bases para el cultivo de capacidades afectivas, cognitivas y sociales- impacta negativamente no sólo en la formación artística de infantes, sino también en sus futuras capacidades creativas y apreciativas, las que juegan un rol más allá de lo estrictamente artístico. 
Por otro lado, si bien la institucionalidad educacional está consciente de la importancia de la formación artística infantil, ello no se ha traducido en la existencia de programas que permitan que los educadores de párvulos seamos capaces de producir en el aula instancias reales de expresión y creación. Las Bases Curriculares de la Educación Parvularia definen los lenguajes artísticos como la "capacidad creativa para comunicar, representar y expresar la realidad a partir de la elaboración original que hacen los niños desde sus sentimientos, ideas, experiencias y sensibilidad" (MINEDUC, 2005: 65). El MINEDUC (2013) ha sostenido que escuelas y jardines deben abrirse a una educación artística integradora. Pero el pregrado nacional carece de asignaturas y prácticas que entreguen una adecuada formación teórica en la materia y estrategias didácticas apropiadas para el aula. Por ello, prevalecen malas prácticas pedagógicas; nuestras aulas parvularias reducen el arte a técnicas básicas de desarrollo motor fino, tal como arrugar papel, colorear y rellenar dibujos prediseñados, por lo tanto dejando fuera de la vida de muchas niñas y niños, ámbitos tales como la apreciación estética, la capacidad creadora y la libertad expresiva.

De esta forma, dejo abierto el espacio para discusión, donde sea posible un debate acerca de la relevancia de las artes y cómo podemos avanzar en mejorar nuestra preparación en didácticas específicas y saberes disciplinarios, para ser un aporte real en la resignificación de la educación artística inicial.

\section{Referencias bibliográficas}

Lowenfeld, V., \&Brittain, W. L. (1980). Desarrollo de la capacidad creadora. Buenos Aires: Kapelusz.

MINEDUC (2005). Bases Curriculares de la educación parvularia. Santiago, Chile.

MINEDUC (2013). Orientaciones pedagógicas para implementar lenguajes artísticos en la escuela. Santiago, Chile. 